Dr. Cox's book is an epitome of all that is required and known to date. It contains references to all the most modern authors, a list of contraceptives, chemical and mechanical, with the manufacturers' names and addresses. There is also given a useful list of rules for the patient to observe if she is to achieve success and avoid dangers incident to contraception. In fine it is a most valuable addition to modern medical literature.

\section{MEDICO-LEGAL ASPECTS OF THE RUXTON CASE.}

By John Glaister, M.D., D.Sc., Barrister at Law, Regius Professor of Forensic Medicine, University of Glasgow, and

JAMES COUPER BRASH, M.A., M.D., F.R.C.S.Ed., Professor of Anatomy, University of Edinburgh. Edinburgh:

E. and S. Livingstone. 1937. Pp. 284. 21/-.

This book is unique as a monograph for the medico-legal library. In the past have been published the famous series of volumes recording important criminal trials, but never before has a book been produced which deals exclusively with the scientific work in the laboratory with regard to one criminal case, and its presentation in Court.

It is also an outstanding record of a case where the materials produced for investigation demanded the co-operation of a number of experts, each a specialist in his own department. Mention may be made of the medico-legal experts, anatomists, serologists and dental surgeons.

It illustrates well the fact that a medicolegal expert is in himself not sufficient to carry out the necessary thorough investigation, and that many minds, each an expert in his own speciality, should co-operate in unravelling a mysterious problem under the guiding hand of the medico-legal expert.

The Ruxton Case will long remain a classic with regard to the identification of human remains, and in this respect, the work which was carried out by the anatomists is unique. It is good that a detailed description of this has been put on permanent record. The work of the dental surgeons also shows what meticulous care was taken in a lengthy and laborious investigation with regard to the teeth and jaws of the two murdered women.
The book is well illustrated, as it should be in such a volume as this, and the whole story of the gradual piecing together of the evidence which was eventually to bring Ruxton to the scaffold reads with extraordinary thrilling interest.

It will be of particular value to those who are engaged in medico-legal work, and should be read by all who are pursuing postgraduate study in forensic medicine.

\section{A SURVEY OF CHRONIC RHEUMATIC DISEASES.}

(Contributed by contemporary authorities in commemoration of the bicentenary of the Royal National Hospital for Rheumatic Diseases, Bath, 1738-1938.)

Compiled under the direction of the following editorial committee: R. G. GoRDON (Chairman), J. BARNES BURT, R. Waterhouse, G. P. R. Aldred-Brown, F. J. Poynton, G. D. Kersley. Humphrey Milford, Oxford University Press. 1938. London, New York, Toronto. Pp. 338, illustrated. Price 18/- net.

The International Congress on Rheumatism and Hydrology has met quite recently, there has been a Trans-Atlantic broadcast on rheumatism, and now Bath, one of the oldest spas in England, has produced a survey of the rheumatic diseases.

Truly, rheumatism, so long neglected, has come into its own at last!

The Royal National Hospital for Rheumatic Diseases, better known as the Royal Mineral Water Hospital, finds that it cannot cope with the demands for its services, and that it has become necessary for it to find a new site and new buildings, and in a foreword has been sketched a brief history of the work that has been done within its doors for the last two hundred years.

Thirty contributors have combined to make the survey complete and to the point, and they hail from all over the world, so that an enormous amount of work, and a long time must have been necessary to correlate and co-ordinate their work.

All the problems which continually confront rheumatologists are dealt with here, and the fact that they still are problems is rather a depressing thought, for indeed, although treatment has advanced a long way, essential ætiology still lags behind, and there seems little doubt that an entirely new angle will have to be taken on the rheu- 